\title{
Timed Average Mean Maximum Velocity (TAMMV) of Cerebral Blood Flow of Children and Adolescents with Sickle cell Disease: correlation with clinical and hematological profiles in country
}

\author{
Bartholomew Chukwu', Lyra Menezes ${ }^{2}$, Thiago Fukuda ${ }^{3}$, Jamary Filho ${ }^{3}$, Marilda Goncalves ${ }^{4}$ \\ 1. Department of Paediatrics, Faculty of Medical Sciences, University of Nigeria, Nsukka \\ 2. Hospital Univesitario Professor Edgard Santos, Paediatric Haematology Service, Universidade Federal de Bahia, Brazil \\ 3. Ambulatorio Pediatrico de doenca cerobrovascular, Universidade Federal da Bahia, Brazil \\ 4. Departmento de Anelises Clinicas e Toxicalogicas, Facuidade da Farmacia, Universidade Federal da Bahia, Brazil
}

Correspondence: Bartholomew Chukwu (barth.chukwu@unn.edu.ng)

\section{Background \\ Abstract}

Detection of abnormal TAMMV with transcranial Doppler is fundamental in primary stroke prevention in children with sickle cell disease (SCD). The study aimed at evaluating TAMMV and correlating it with clinical and hematological profiles of children and adolescent with SCD.

Methods

Transcranial Doppler was performed on subjects aged 2-16 years, using a $2 \mathrm{MHz}$ probe placed over the transtemporal windows. Pulse oximetry was used to determine the peripheral oxygen saturation while clinical and hematological profiles were retrieved from their medical records.

Results

One hundred and thirty five patients were recruited. The mean TAMMV was $125 \mathrm{~cm} / \mathrm{s}$. Patients with HbSS had a significantly higher TAMMV $(131 \mathrm{~cm} / \mathrm{s})$ than those with $\operatorname{HbSC}(107 \mathrm{~cm} / \mathrm{s})$. Only one $(0.74 \%)$ patient had abnormal TAMMV. TAMMV correlated inversely with oxygen saturation, Hct and patient's age, and positively with white cell and platelet counts. Previous history of acute chest syndrome (ACS) and recurrent painful crises increased the risk of development of abnormal and conditional velocity.

Conclusion

Frequency of abnormal TAMMV in this study was low. Younger children and those with HbSS had higher TAMMV. Age, oxygen saturation and haematocrit correlated negatively while white cell and platelet counts correlated positively with TAMMV. Previous history of ACS and recurrent bone pain were associated with increased risk of having abnormal and conditional TAMMV.

Key words: sickle cell disease, TAMMV, Transcranial Doppler, children, adolescents, Salvador.

\section{Introduction}

Sickle cell disease (SCD) is the commonest genetic disorder worldwide. In Brazil, the frequency of sickle cell trait (SCT, HbAS) and prevalence of SCD range from $1.1 \%$ to $9.8 \%$ and 0.8 to 60 per 100,000 births respectively. It is estimated that about 700-1000 children are born annually in Brazil with SCD ${ }^{1,2,3,4}$. Salvador, Bahia, has the highest burden of both the trait and the disease, with frequency of SCT and prevalence of SCD being $9.8 \%$ and $0.17 \%$ respectively ${ }^{5,6}$.

Cerebrovascular accident (CVA) or stroke is a devastating complication of SCD and up to $11 \%$ of children with HbSS genotype are at risk of developing stroke before the age of 20 years, with highest incidence occurring between 2-5 years ${ }^{7}$. The incidence of stroke among Brazilian children with SCD ranged from 17.2-27.3\% ${ }^{8}$. Proliferative vasculopathy of large intracranial internal carotid arteries and their proximal branches is the pathophysiological basis for development of ischemic stroke in SCD, although micro-infarcts in the deep white matter and diffuse arteriolar thickening have been reported in some neuropathological studies with normal cerebral angiograms in cases of acute clinical stroke $e^{9,10,11}$ Risk factors for occurrence of stroke in
SCD include anemia, leukocytosis, thrombocytosis, previous stroke, silent cerebral infarction, and systemic hypertension with abnormal TAMMV as the most important risk factor ${ }^{7,12}$. Detection of abnormal TAMMV with transcranial Doppler (TCD) and prophylactic blood transfusion are fundamental to primary stroke prevention in $\mathrm{SCD}^{13}$.

Apart from TCD, are there other parameters that may indicate an increased TAMMV in children with SCD? Previous studies on TCD in Brazilian children were mainly on relationship between TAMMV and haemoglobin concentration $^{14,15}$ and there is paucity of data on TAMMV and its relationship with other haematological parameters. The aim of the present study was to evaluate TAMMV of children and adolescents with SCD, detect those with conditional and abnormal TAMMV and correlate TAMMV with hematological (haematocrit, WBC, platelets) and clinical profiles of the patients.

\section{Materials and Methods}

This cross sectional study was conducted at the Pediatric Hematology outpatient clinic of Professor Edgard Santos University Hospital, Salvador, Brazil, between March 2016 
and Feb. 2017. Patients included in the study were aged 2-16 years, confirmed to have SCD, in a steady state while patients with past history of stroke or on prophylactic blood transfusion or had received blood transfusion for any other reason within the preceding 3 months were excluded. Patients in steady state were regarded as those that did not present with any acute illness necessitating emergency visit or hospital admission in the past four weeks and did not have recurrent infection or inflammation within the past four weeks before TCD evaluation ${ }^{16}$. All the patients who presented to the clinic over the study period and met the inclusion criteria were recruited consecutively for TCD evaluation. Clinical risk factors of stroke including past history of stroke, ACS or pneumonia, recurrent bone pain and priapism within the preceding twelve months were obtained from patients or caregivers and verified from the patients' medical records. Recurrent bone pain crisis was regarded as three or more painful episodes that required visit to the emergency room or hospital admission within the past 12 months. The steady state hematological parameters and use of hydroxyurea ( $\mathrm{HU}$ ) were also obtained from patients' medical records. The steady state hematological parameters were taken as values obtained within the preceding 3 months without blood transfusion; and included, hemoglobin concentration, hematocrit, reticulocyte, WBC, neutrophil, monocyte, and platelet counts. It was ensured that patients on $\mathrm{HU}$ had been on stable dose for at least six months before TCD evaluation.

The arterial oxygen saturation $\left(\mathrm{SpO}_{2}\right)$ was determined with pulse oximeter (Geratherm Medical, Germany) placed on the right index finger of the patient at the time of TCD. Conventional TCD screening as recommended by Stroke prevention trial in SCA (STOP) and the Brazilian guidelines for TCD in children and adolescents with SCD was performed, using a single non-imaging device Doppler probe (2MHZ) transducer (Sonatek, Viasys Healthcare and Cardinal Health, USA) on the trans-temporal windows. ${ }^{17,18}$ The indications, procedures, advantages and risks of the examination were explained to the patients and/or caregivers before the examination.

The examination was done while patient was in supine position, awake, calm, and alert but not allowed to sleep because increase in $\mathrm{CO}_{2}$ during sleep can increase TAMMV. It was also ensured that patient was not febrile, agitated or crying during examination as these may falsely increase TAMMV. While patient was lying supine and looking contra laterally, the examiner sat at the head of the bed with easy access to the instruments. The lubricated $2 \mathrm{MHz}$ frequency TCD probe was placed over the transtemporal window to insonate the basal cerebral arteries. The arteries were identified based on relative direction of the probe within the acoustic window, direction of blood flow relative to the probe, and depth of insonation. The distal internal carotid artery (ICA) or its bifurcation was identified at depths of 55 to $65 \mathrm{~mm}$ with simultaneous flow away and towards the probe. The middle cerebral artery (MCA) was identified at depths of 35 to $55 \mathrm{~mm}$ with blood flow towards the probe while the anterior cerebral artery (ACA) was viewed at depths of 60 to $70 \mathrm{~mm}$ with blood flow away from the probe. Both audible and visual signals of the Doppler wave form were assessed with the aim of recognizing turbulence and other audible clues that suggest high velocities; and with the goal of obtaining the "cleanest," sharpest and highest velocity signal. The timed average mean maximum velocities (TAMMV) in the proximal MCA and distal ICA were recorded from both hemispheres according to the STOP protocol for $\mathrm{SCD}^{17}$.

Written informed consent was obtained from caregivers and ascent from children of seven years and above. Ethical approval was obtained from the Institutional Review Board before commencing the study (IR 314.636).

The data were analyzed with statistical software (STATA 10, College Station, Tex: Stata Corp) and (SPSS 20.0, Armonk, NY: IBM Corp). Interval variables were presented as means and standard deviations for parametric variables or median and range for non-parametric variables. Categorical variables were presented in form of tables, proportions and percentages. Test of significance was assessed using Student's-T test for parametric interval variables and Mann Whitney test for non-parametric variables. Chi-square test or Fischer's exact test was used to test for significant difference between categorical variables. Correlations were assessed using Spearman's correlation coefficients. Eta coefficient was used to determine the strength of association between categorical independent variable (class of TAMMV) and interval dependent variables. Linear regression analysis was used to establish associations between dependent (TAMMV) and independent variables (age, $\mathrm{SpO} 2$, haematocrit, WBC, platelets, reticulocytes) after log transformation of the data. Odds of having abnormal or conditional TCD result were calculated for those that had history of clinical risk factors under study. Test of significance was set at $\mathrm{p}<0.05$.

\section{Results}

\section{Patients' Characteristics}

The subjects comprised 74 (54.8\%) females and 61 (45.2\%) males with median age of 8 years (2-16). Ninety three $(68.9 \%)$ of them had HbSS genotype, 41 (30.4\%) HbSC and one $(0.7 \%), \mathrm{S} \beta+$ thalassemia genotype. Fifty one $(37.8 \%)$ of the patients were taking $\mathrm{HU}$ as at the period of TCD screening for various indications, such as recurrent bone pain, past history of acute chest syndrome, or previous abnormal TCD report. The median weight, height and body mass index (BMI) of the patients were $23.6(11-75.2) \mathrm{kg}, 1.3$ (0.8-1.8) $\mathrm{M}$ and 16.3 (10.7- 27.3) $\mathrm{Kg} / \mathrm{M}^{2}$ respectively.

\section{Transcranial Doppler screening}

The median of the TAMMV was $125 \mathrm{~cm} / \mathrm{s}$ (74.4-202). One patient $(0.74 \%)$ had abnormal result $(\geq 200 \mathrm{~cm} / \mathrm{s})$ while 18 $(13.33 \%)$ had conditional TAMMV $(170-199 \mathrm{~cm} / \mathrm{s})$. None had low TCD result $(<70 \mathrm{~cm} / \mathrm{s})$.

The females had a median TAMMV of 125.5 (74.7-199) $\mathrm{cm} / \mathrm{s}$ in comparison with the males' $122(74.4-202) \mathrm{cm} / \mathrm{s}$, with no significant difference (Mann-Whitney test, $\mathrm{p}=0.5$ ). One $(1.6 \%)$ of the males had abnormal result, $8(13.1 \%)$ had conditional results while $10(13.5 \%)$ of the females also had conditional results, with no significant difference (Fischer's exact, $\mathrm{p}=0.7)$.

The age group, 6-9 years had the highest median TAMMV of $131 \mathrm{~cm} / \mathrm{s}$ while those aged $14-16$ years had the lowest velocity of $111 \mathrm{~cm} / \mathrm{s}$ (Kruskal-Wallis test, $\mathrm{p}=0.01$ ) as shown in table 1 . While the only abnormal TCD result was recorded in the age group $2-5$ years, $88.9 \%(16 / 18)$ of the conditional results was in the under 10.

TAMMV did not differ significantly (Wilcoxon signed-rank test: $z=-0.9, p=0.4)$ between the right $(118 \mathrm{~cm} / \mathrm{s})$ and left $(120 \mathrm{~cm} / \mathrm{s})$ middle cerebral arteries, nor among patients on $(128 \mathrm{~cm} / \mathrm{s})$ or not on $(121 \mathrm{~cm} / \mathrm{s})$ HU therapy (Mann-Whitney 
Table 1: TCD results based on patients'age.

\begin{tabular}{|c|c|c|c|c|c|}
\hline $\begin{array}{l}\text { Age category } \\
\text { (years) }\end{array}$ & & & TCD result & & \\
\hline & $\mathrm{N}(\%)$ & $\operatorname{Median}(\mathrm{cm} / \mathrm{s})$ & Normal (\%) & Conditional (\%) & Abnormal (\%) \\
\hline $2-5$ & $41(30.4)$ & 127.0 & $32(23.7)$ & $8(5.9)$ & $1(0.7)$ \\
\hline $6-9$ & $43(31.8)$ & 131 & $35(25.9)$ & $8(5.9)$ & $0(0)$ \\
\hline $10-13$ & $36(26.7)$ & 121.5 & $26(19.3)$ & $(0.7)$ & $0(0)$ \\
\hline $14-16$ & $15(11.1)$ & 111 & $23(17.0)$ & $1(0.7)$ & $0(0)$ \\
\hline
\end{tabular}

Table 2: Hematological variables and $\mathrm{SpO}_{2}$ based on TCD result.

\begin{tabular}{|c|c|c|c|c|c|c|c|c|c|}
\hline TCD & Hct (\%) & $\mathrm{Hb}(\mathrm{g} / \mathrm{dl})$ & $\mathrm{SpO}_{2}(\%)$ & WBC (/L) & ANC (/L) & AMC (/L) & Platelets (/L) & Retics (\%) & $\mathrm{HbF}(\%)$ \\
\hline Normal & 27.4 & 9.2 & 97 & 9200 & 5388 & 727 & 369,148 & 3.6 & 9.2 \\
\hline Conditional & 23.2 & 7.8 & 94 & 14250 & 8216 & 1388 & 538,300 & 8.3 & 6.3 \\
\hline Abnormal & 21 & 6.9 & 92 & 12300 & 6396 & 1250 & 529,000 & 4.4 & 3.2 \\
\hline$P$ value & 0.008 & 0.005 & 0.0002 & 0.01 & 0.004 & 0.0001 & 0.0003 & 0.1 & 0.05 \\
\hline
\end{tabular}

Values indicated in the table were median values, except hemoglobin which was as mean value. Hct, Hematocrit; Hb, Hemoglobin; Retics, Reticulocyte count; HbF, Fetal hemoglobin; ANC, Absolute neutrophil count; AMC, Absolute monocyte count.

test: $\mathrm{p}=0.4)$.

Comparing TAMMV among the two major genotypes, it was observed that patients with HbSS had higher median TAMMV $(131 \mathrm{~cm} / \mathrm{s})$ compared to those with HbSC $(107 \mathrm{~cm} / \mathrm{s})$, with a statistically significant difference (MannWhitney test, $\mathrm{p}<0.0001)$. Only the HbSS patients had abnormal or conditional velocity $(\mathrm{OR}=10.8,95 \% \mathrm{CI}=$ 1.58-485.5, $\mathrm{p}=0.005)$.

The study compared the hemoglobin oxygen saturation (SpO2) and hematological indices among the patients in relation to their TCD results (Table. 2). It was observed that patients with abnormal or conditional results had lower SpO2 (<95\%) compared to those with normal result with a statistically significant difference (Kruskal-Wallis test: $\mathrm{p}=$ 0.0002). Patients with abnormal or conditional TCD results also had lower mean hemoglobin concentration compared with those with normal results. One-way analysis of variance (ANOVA) indicated a statistically significant difference in the mean hemoglobin concentrations (ANOVA: $\mathrm{F}=5.58$, $\mathrm{p}=0.005)$. 
Table 3: Median haematological variables compared between patients on hydroxyurea and those not taking the drug

\begin{tabular}{l|c|l|l|}
\hline Variables & Hydroxyurea & Median & P value \\
\hline Total WBC $(\mu l)$ & Yes & 9600 & \\
& No & 9700 & 0.7 \\
Hct $(\%)$ & Yes & 27.3 & \\
& No & 27.0 & 0.9 \\
ANC $(\mu l)$ & Yes & 4317 & \\
& No & 4816 & 0.5 \\
AMC $(\mu l)$ & Yes & 689 & \\
& No & 765 & 0.5 \\
Platelets $(\mu l)$ & Yes & 406000 & \\
& No & 389500 & 0.7 \\
Retics $(\%)$ & Yes & 4.7 & \\
& No & 4.5 & 0.9 \\
\hline ANC; absolute neutrophil count, AMC; absolute monocyte count, Retics; reticulocyte count \\
\hline
\end{tabular}

Table 4: Correlation between TAMMV and patients' hematological indices and $\mathrm{SpO}_{2}$

\begin{tabular}{lcc|l|l|}
\hline Variable & $\mathrm{N}$ & Spearman $\square$ & P value \\
\hline Age & 135 & -2.0 & 0.02 \\
$\mathrm{SpO}_{2}$ & 135 & -0.35 & 0.0001 \\
Hemoglobin & 75 & -0.50 & 0.0000 \\
Hematocrit & 75 & -0.50 & 0.0000 \\
Reticulocyte count & 72 & -0.51 & 0.0000 \\
HbF & 72 & 0.03 & 0.8 \\
Total WBC & 75 & 0.34 & 0.003 \\
Platelet count & 75 & 0.34 & 0.003 \\
ANC & 75 & 0.30 & 0.01 \\
AMC & 75 & 0.53 & 0.0000
\end{tabular}

ANC, absolute neutrophil count; AMC, absolute monocyte count; HbF, fetal hemoglobin; TAMMV, Timed average mean maximum. 
Table 5: Association between class of TAMMV (normal, conditional, abnormal) and the independent variables

\begin{tabular}{|c|c|c|c|}
\hline & & & Eta coefficient \\
\hline & & $\begin{array}{l}\text { Class of TAMMV (normal, conditional, } \\
\text { abnormal) }\end{array}$ & \\
\hline Nominal by Interval & Eta & $\mathrm{SpO} 2$ & 0.415 \\
\hline & & Age & 0.175 \\
\hline & & Haemoglobin & 0.379 \\
\hline & & Haematocrit & 0.367 \\
\hline & & Total WBC & 0.263 \\
\hline & & Absolute neutrophil count & 0.310 \\
\hline & & Absolute monocyte count & 0.509 \\
\hline & & Platelet count & 0.449 \\
\hline & & Reticulocyte count & 0.147 \\
\hline & & Fetal haemoglobin & 0.256 \\
\hline
\end{tabular}

0.2-0.39 indicate weak association, $0.4-0.69$ indicates medium association, $\geq 0.7-1$ indicates strong association

Table 6: Multiple linear regression analysis between TAMMV and its independent predictors.

\begin{tabular}{|c|c|c|c|c|}
\hline Variables & Coef. & $T$ & $P$ value & $95 \% \mathrm{Cl}$. \\
\hline Age & -0.0006 & 3.2 & 0.002 & $0.0009-0.0002$ \\
\hline $\mathrm{SpO}_{2}$ & -0.0002 & 0.36 & 0.7 & $-0.007-001$ \\
\hline $\mathrm{Hb}$ & -0.004 & -1.8 & 0.08 & $-0.0005-0.0008$ \\
\hline WBC & 1.97 & 3.17 & 0.002 & $3.2-7.3$ \\
\hline ANC & 1.84 & 2.23 & 0.03 & $1.93-3.48$ \\
\hline AMC & 9.9 & 3.95 & 0.000 & $0.0002-4.9$ \\
\hline Platelets & 1.03 & 1.42 & 0.16 & $2.48-4.22$ \\
\hline Retics & 0.00035 & 1.54 & 0.13 & $0.0001-0.0008$ \\
\hline $\mathrm{HbF}$ & -0.005 & -2.79 & 0.007 & $0.0009-0.0001$ \\
\hline
\end{tabular}

Percentage of $\mathrm{HbF}$ was lower in patients with abnormal $(3.3 \%)$ or conditional $(6.3 \%)$ TCD results than those with normal $(9.2 \%)$ results, but the difference was not significant (Kruskal-Wallis test: $\mathrm{p}=0.05)$. Following a similar pattern, there was no significant difference (Kruskal-Wallis test: $\mathrm{p}=$ $0.1)$ in the reticulocyte count among patients with normal $(4.4 \%)$, conditional $(8.3 \%)$ or abnormal $(3.6 \%)$ TCD results. It was observed that patients with conditional or abnormal TCD results had higher white cell and platelet counts than those with normal results. Test of significance (KruskalWallis test) also indicated that the differences in WBC and platelet counts were statistically significant.

The haematological profiles of patients on hydroxyurea were comparable with those not taking the drug as shown in table 3. Most of the parameters were higher in children that were not on hydroxyurea, although the differences were not significant. The haematocrit was higher in children on hydroxyurea.

As shown in table 4, Spearman's correlation analysis indicated that patients' age, SpO2, and hematocrit negatively correlated with TAMMV. Total leukocyte, neutrophil, monocyte, platelet, and reticulocyte counts had positive correlation with TAMMV. These findings demonstrate that increased TAMMV is associated with younger age, low SpO2, low hematocrit/hemoglobin and elevated leukocyte, neutrophil, monocyte, platelet, and reticulocyte counts. There was no correlation between $\mathrm{HbF}$ concentration and TAMMV. 
The strength of association between the class of TAMMV (normal, conditional, abnormal) and the dependent variables is as in table 5. While the strength of association between class of TAMMV and oxygen saturation, absolute monocyte count and platelet count was medium, that with age, haematocrit, fetal haemoglobin was a weak association.

After log transformation of the non-parametric variables, a multiple linear regression model was used to assess for a linear relationship between TAMMV and the independent variables (age, SpO2, haematocrit, WBC, platelets, reticulocytes). This regression model showed that the independent variables statistically significantly predicted the dependent variable $($ TAMMV), $\mathrm{F}(10,60)=8.87, \mathrm{p}=0.0000)$, although responsible for only $60 \%$ of the variability of TAMMV $(\mathrm{R} 2=0.5964)$. Young age and low $\mathrm{HbF}$ had negative association with TAMMV while total leukocyte, neutrophil, and monocyte counts independently had positive association with TAMMV, when other variables were held constant $(\mathrm{p}=$ $0.002,0.002,0.03,0.000$, and 0.007 respectively)-Table 6 .

A risk analysis showed that patients who have had ACS in the preceding year were sixteen times at risk of having abnormal or conditional TCD result compared to those without the complication. Out of the 23 patients that suffered ACS, $12 \mathrm{had}$ altered TAMMV (Odds ratio $=16.4 ; \mathrm{X} 2=33.3, \mathrm{p}=$ $0.000,95 \% \mathrm{CI}=4.6-58.6)$. In the same vein, 17 of 66 that had recurrent painful crises had abnormal or conditional result $($ Odds ratio $=11.3, \mathrm{X} 2=14.1, \mathrm{p}=0.0002,95 \% \mathrm{CI}=$ $2.4535-103.5636)$. No case of priapism was recorded in the present study.

\section{Discussion}

Since the revelation from STOP clinical study with TCD in the late 1990s, the incidence of stroke in children with SCD has markedly reduced, compared to the pre-TCD era ${ }^{13}$. TCD identifies those at high risk of developing stroke and by instituting prophylactic blood transfusion program on them, stroke and other complications of SCD are minimized ${ }^{13,19}$.

In this study, the prevalence of abnormal TCD result was comparable to $1.6 \%$ and $2.6 \%$ reported by Hokazono et al and Melo et al., as well as that by Leite et al. in different parts of Brazil ${ }^{14,20,21}$. However, it was lower than that reported in Nigeria $(8.4 \%)$ by Lagunju et al and in Iraq $(13.33 \%)$ by Hasan et al..$^{22,23}$. The difference in prevalence could have resulted from use of hydroxyurea in Brazilian children. Access and adherence rate of hydroxyurea among sickle cell patients is high in Brazil ${ }^{24}$. The differences in prevalence could also be due to differences in the number of patients screened or other factors including genetic. Genetic factors associated with increased risk of stroke in SCD include the haplotype, co-inheritance of alpha thalassemia, persistence of $\mathrm{HbF}$ production as well as inheritance of genes involved in inflammation, hypoxia, adherence molecules and coagulation ${ }^{25}$.

There is tendency for conditional TCD to convert to abnormal result, which increases the risk of stroke. It is therefore imperative that measures be put in place to avert this conversion $^{26}$. Apart from 3-6 monthly monitoring of TCD velocity in those with conditional results, no intervention measure is yet recommended, although some researchers have demonstrated the effectiveness of $\mathrm{HU}$ in preventing conversion of conditional to normal result, thereby reducing the risk of stroke in children with $\mathrm{SCD}^{27}$.

Patients with SCA had higher TAMMV compared to other genotypes. This was in agreement with report by Hokazono et al. ${ }^{14}$ In the present study, all the abnormal and conditional results were from patients with HbSS genotype. Vieira et al. observed also that patients with HbSS had significantly higher TAMMV compared to HbSC disease patients and suggested a lower cut-off point for the latter patients ${ }^{15}$. HbSS genotype confers is a more severe type of SCD compared to other genotypes $^{28}$. Apart from higher prevalence of abnormal or conditional TAMMV and higher risk of CVA, patients with genotype HbSS have higher rates of hemolysis, lower hemoglobin, $\mathrm{SpO} 2$, and cardiac and other complications when compared with other genotypes ${ }^{29}$. In a comparative study of chronic kidney disease among SCD patients, it was observed that homozygous HbS patients were more severely affected than HbSC counterparts ${ }^{30}$. HbSS and $\mathrm{HbS} \beta 0$ -thalassemia generally present most severe clinical and hematological symptoms while HbSC and $\mathrm{HbS} \beta+$-present less severe disease.

This study also observed that the age group with the highest median of TAMMV was 6-9 years. Thereafter, TAMMV decreased with increasing age. This trend was in agreement with report by Lagunju et al and Makani et al. among patients with HbSS genotype and conformed to the general pattern of TAMMV in children without SCD. ${ }^{22,31}$ According to Sch $\square$ ning et al., TAMMV increases markedly from 3 years of age and peaks at about the age of 6 years, and gradually decreasing until 15 years when it reaches a constant value ${ }^{32}$. Brass et al. also observed that cerebral blood flow reaches maximum at about the 6th year of life, with a direct relationship between it and blood flow velocity ${ }^{33}$. This study also established a significant inverse correlation between TAMMV and patient's age. This trend, in combination with other factors such as genetic and environmental factors could be the reason why vasculopathy in SCD, abnormal TCD, and stroke are commoner in younger children with SCD. Other complications of SCD commoner in the younger age group include ACS, splenic sequestration and parvovirus B19 infection with aplastic crisis. These complications have a common association with infection, either viral or bacterial $^{34,35,36}$. Therefore, it may be conceivable to think that sickle cell vasculopathy is also related to infections among this age group. Further studies are required to prove or debunk this conception.

It may be surprising to note that there was no significant difference in TAMMV between those taking HU and their counterparts who were not taking the medication. It is known that HU can reverse abnormal TAMMV to conditional or normal and it may be possible that the patients on $\mathrm{HU}$ previously had conditional or abnormal TAMMV that reversed on taking the drug. However, we did not document the specific indications for use of $\mathrm{HU}$ among the individual patients.

A significant negative correlation was noted between TAMMV and $\mathrm{SpO}_{2}$, hemoglobin and hematocrit. This finding concurred with previous studies ${ }^{22,31,37}$. Blood desaturation impairs oxygen delivery to the cerebral tissue and predisposes to CVA. Patients with SCD have chronic anemia arising from chronic hemolysis and recurrent infections. In anemia and desaturation, the circulatory system responds by lowering peripheral resistance, increasing cardiac output, which increases cerebral blood flow through increase in blood flow velocity ${ }^{38}$. Increased blood flow triggers turbulent flow, predisposing to vascular endothelial 
damage, inflammation, hyperplasia and hypertrophy of vascular smooth muscle, stenosis, cerebral ischemia, and increased risk stroke ${ }^{39}$. Maintaining a stable hemoglobin concentration at or close to $10 \mathrm{~g} / \mathrm{dl}$ by transfusions or drugs that increase the level of $\mathrm{HbF}$ and hemoglobin such as HU reduces the risk of abnormal TAMMV and stroke in children with SCD. Increased hemoglobin level improves oxygen transport and delivery to the brain, thereby reducing the risk of stroke. Chronic transfusion increases the normal hemoglobin level, reduces hypoxia and percentage of $\mathrm{HbS}$ $(<30 \%)$ and improves oxygen saturation and delivery to cerebral and other tissues.

The positive correlation between TAMMV and leukocyte, neutrophil and monocyte counts, platelet count and reticulocyte was also observed by Ismail etal in Kano, Nigeria ${ }^{40}$, Adekunle et $\mathrm{al}^{41}$ in Lagos, Nigeria also observed a significant correlation between TAMMV and leukocytosis and this could be ascribed to the fact that these cells are active participants in the chronic inflammatory process in SCD. Other studies have also shown higher counts and activation of these cells in patients with SCD, and more so in those with complications of the disease $e^{21,42}$. Reticulocyte count is an indirect marker of intravascular hemolysis, a major pathological process in SCD in which free hemoglobin and heme are released into the circulation, with consequent scavenging of nitric oxide, endothelial injury, elaboration of proinflammatory cytokines and cellular adhesion molecules. The WBC in the multiple linear regression model independently predicted cerebral blood flow velocity, a major risk factor in development of CVA in children with SCD. Study by Conran and colleagues observed that severity of SCD is associated with increased WBC count while a reduction ameliorates the severity of the disease ${ }^{7,43}$. The platelet count, absolute monocyte count and oxygen saturation had medium strength of association with the class of TAMMV as these are important risk factors for development of conditional or abnormal TAMMV and stroke in sickle cell disease.

In the multiple linear regression model, patient's age, total WBC, absolute neutrophil and monocyte counts, and HbF, were independently associated with cerebral blood flow velocity. Studies by Quinn et al observed inverse relationship between TAMMV and $\mathrm{SpO}_{2}$ and hematocrit ${ }^{37}$. Also in the multivariate model by Makani et al, it was observed that low $\mathrm{SPO}_{2} \leq 95 \%$, young age and a history of fever were associated with high cerebral blood flow velocity ${ }^{31}$. There is a dearth of information on a direct relationship between TAMMV and WBC, although Colombatti et al recently report an association between it and increased leukocyte count ${ }^{44}$. The final consequence of cerebral vasculopathy in SCD is vascular stenosis, which results from vascular smooth muscle remodeling, hyperplasia and hypertrophy. All these result from chronic inflammation, which is directly or indirectly triggered by hemolysis, adherence of sickle red cells and other cells to vascular endothelium, elaboration of proinflammatory cytokines and activation of proinflammatory cells ${ }^{45}$.

Children who had suffered ACS/pneumonia or recurrent painful crises had higher probability of having an abnormal or conditional cerebral blood flow velocity. ACS is an acute illness characterized by fever, acute respiratory symptoms, new pulmonary infiltrates on chest X-ray and hypoxia. This complication may result from pulmonary infection (pneumonia) or fat embolism from necrotic bone infarction, resulting in fall in pulmonary oxygen tension, oxygen desaturation, sickle hemoglobin polymerization, red blood cell sickling leading to hemolysis and inflammation ${ }^{35}$. ACS is a known risk factor of stroke and other encephalopathies in patients with $\mathrm{SCA}^{7,46}$. Pulmonary hypoxia from ACS can predispose to reduction in delivery of oxygenated blood to cerebral tissues with resultant cerebral vascular endothelial injury, cerebral arterial smooth muscle modeling, stenosis with cerebral ischemia and stroke. Recurrent vasoocclusion and pain with subsequent reperfusion injury, endothelial activation, inflammation and vascular smooth muscle hyperplasia and hypertrophy predisposes to cerebral vessel stenosis and increased risk of elevated TAMMV and ischemic stroke in sickle cell disease.

\section{Conclusion}

The frequency of abnormal TCD result was low in children with SCD in Salvador. Children with HbSS and those with past history of acute chest syndrome or recurrent vasoocclusive episodes are more likely to have abnormal result while TAMMV correlated negatively with hematocrit, peripheral oxygen saturation and age, and positively with white cell and platelet counts. In facilities where universal TCD screening is not possible, priority may be given to those with HbSS, low oxygen saturation, past history of ACS, recurrent painful crisis or abnormally high leukocyte and platelet counts.

The study was limited by a few number of patients with abnormal or conditional TCD results, making it difficult to have a statistically reliable conclusion. The retrieval of haematological profile of the patients from the medical records was also a limitation as the values may not represent the true values as at time of TCD. There was also no documentation of the specific indications for use of $\mathrm{HU}$ among individual patients on the medication. Further studies with more patients and documentation of blood cellular values at time of TCD are required.

\section{References}

1.Okumura JV, Lobo CL, Bonini-domingos CR. Beta-S globin haplotypes in patients with sickle cell anemia: one approach to understand the diversity in Brazil. Rev Bras Hematol Hemoter. 2013; 35: 71-72

2.Lobo CL, Cançado RD, Leite AC et al. Brazilian guidelines for transcranial Doppler in children and adolescents with sickle cell disease. Rev Bras Hematol Hemoter. 2011; 3(1): 43-8

3.Bezerra MA, Santos M.N, Araujo AS et al. Molecular variations linked to the grouping of beta- and alpha-globin genes in neonatal patients with sickle cell disease in the state of Pernambuco, Brazil. Hemoglobin 2007; 31: 83-8

4.Sommet J, Alberti C, Couque $\mathrm{N}$ et al. Clinical and haematological risk factors for cerebral macrovasculopathy in sickle cell disease newborn cohort: a prospective study. Br J Haematol. 2016; 172(6): 966-77

5.Adorno EV, Couto FD, Moura JP et al. Hemoglobinopatias em recémnascidos de Salvador, Bahia, Nordeste do Brasil. Cad Saúde Pública. 2005; 21(1): 292-298

6.Rodoldo DC, Joice AJ. Sickle cell disease in Brazil. Rev. brass. hematol. hemoter 2007; 29(3): 203-206

7.Ohene-Frenpong K, Weiner SJ, Sleeper LA et al. Cerebrovascular accidents in sickle cell Disease: rates and risks. Blood 1998. 91(1): 288-294

8.Rodrigues DOW, Ribeiro LC, Sudário LC et al. Genetic determinants and stroke in children with sickle cell disease. J Pediatr (Rio J). 2016; 
92(6): 602-608

9.Fasano R M, Meier ER, Hulbert M. L. Cerebral vasculopathy in children with sickle cell anemia. Blood Cells Mol Dis. 2015; 54: 17 $-25$

10.Gerald B, Sebes JI, Langston J.W. Cerebral infarction secondary to sickle cell disease: arteriographic findings. Am J Roentgenol 1980; 134 : 1209-1212

11.Koshy M, Thomas C, Godwin J. Vascular lesions in the central nervous system in sickle cell disease (neuropathology). J Assoc Acad Minor Phys. 1990; 1(3): 71-78

12.Kwiatowski JL, Granger S, Brambilla DJ et al. and STOP Trial Investigators. Elevated blood flow velocity in anterior cerebral artery and stroke risk in sickle cell disease: extended analysis from STOP trial. Br J Haematol. 2006; 134(3): 333-9

13.Adams R J, McKie VC, Hsu L, Files B, Vichinsky E, Pegelow C. Prevention of a first stroke by transfusions in children with sickle cell anemia and abnormal results on transcranial Doppler ultrasonography. N Engl J Med. 1998; 339(1): 5-11

14.Hokazona M, Silva GS, Silva EM, Braga JP. Results from transcranial Doppler examination on children and adolescents with sickle cell disease and correlation between timed- average maximum mean velocity and hematological characteristics: a cross-sectional study. Sao Paulo Med. 2011; 129(3): 34-138

15.Vieira C, de Oliveira CNC, de Figueiredo LAB, et al. Transcranial Doppler in hemoglobin SC disease. Pediatric Blood \& Cancer. 2017; 64, e26342

16.Ballas, SK. More definitions in sickle cell disease: Steady state v base line data. Am. J. Hematol, 2012; 87: 338

17.Nichols FT, Jones AM, Adams RJ. Stroke prevention in sickle cell disease (STOP) study guidelines for transcranial Doppler testing. J Neuroimaging. 2001; 11: 354-362

18.Lobo CL, Cançado RD, Leite AC et al. Brazilian guidelines for transcranial Doppler in children and adolescents with sickle cell disease. Rev Bras Hematol Hemoter. 2011; 33(1): 43-48

19.Enninful-Eghan H, Moore RH, Ichord R, Smith-Whitely K. \& Kwiatowski JL. Transcranial Doppler screening and prophylactic transfusion program is effective in preventing overt stroke in children with sickle cell disease. J Pediatr. 2010; 157: 479-484

20.Melo HA, Barreto-Filho JAS, Prado RCP, Cipolotti R. Doppler transcraniano em portadores de anemia falciforme: estudo dos parâmetros de fluxo sangüíneo cerebral em crianças de Aracaju, Sergipe. Arq. Neuro-Psiquiatr. 2008; 66(2b): 360-364

21.Leite AC, Carvalhaes de Oliveira RV, Gomes de Moura P, Silva CM, Lobo C. Abnormal transcranial Doppler ultrasonography in children with sickle cell disease. Rev Bras Hematol Hemoter. 2012; 34(4): $307-$ 310

22.Lagunju I, Sodeinde O, Brown B, Akinbami F, Adedokun B. Transcranial Doppler ultrasonography in children with sickle cell anemia: Clinical and laboratory correlates for elevated blood flow velocities. J Clin Ultrasound. 2014; 42(2): 89-95

23.Hasan EH, Jasim TA. Stroke in Sickle Cell Disease, Risk Factors Comparative Study, American Journal of Medicine and Medical Sciences 2016; 6(1): 16-22

24.Campanaro CM, Livinalli A, Souza DL, Varizano VR, \& Estrela HF. Evaluation of Treatment Adherence of Sickle Cell Pediatric patients in Use of hydroxyurea. Blood 2011, 118(21): 4757

25.Hebbel RP, Vercellotti, GM, Nath KA. A Systems Biology Consideration of the Vasculopathy of Sickle Cell Anemia: The need for Multi-Modal Chemo-Prophylaxis. Cardiovasc Hematol Disord Drug Targets 2009; 9(4): 271-292

26.Hankins JS, Fortner GL, McCarville MB et al. The natural history of conditional transcranial Doppler flow velocities in children with sickle cell anaemia. Br J Haematol. 2008; 142(1): 94-99

27.Hankins JS, McCarville MB, Rankine-Mullings B et al. Prevention of conversion to abnormal TCD with Hydroxyurea in sickle cell anemia: A phase III international Randomized clinical Trial. Am J Hematol. 2015; 90(12): 1099-1105

28.Saraf SL, Molokie RE, Mehdi NM et al. Differences in the clinical and genotypic presentation of sickle cell disease around the world. Paediatr Respir Rev. 2014; 15(1): 4-12

29.Nolan VG, Wyszynski DF, Farrer LA, Steinberg MH. Hemolysisassociated priapism in sickle cell disease. Blood, 2005;106: 3264-3267.

30.Drawz P, Ayyappan S, Nouraie M et al. Kidney Disease among Patients with Sickle Cell Disease, Hemoglobin SS and SC. Clin J Am Soc Nephrol. 2016; 11(2): 207-15

31.Makani J, Kirkham FJ, Komba A et al. Risk factors for high cerebral blood flow velocity and death in Kenyan children with Sickle Cell Anaemia: role of haemoglobin oxygen saturation and febrile illness. $\mathrm{Br}$ J Haematol. 2009; 145(4:, 529-532

32. Schöning M \& HARTIG B. Age dependence of total cerebral blood flow volume from childhood to adulthood. Journal of Cerebral Blood Flow \& Metabolism 1996; 16(5): 827-833

33. Brass LM, Prohovnik I, Pavlakis SG, De Vivo DC, Piomelli S, Mohr JP. Middle cerebral artery blood velocity and cerebral blood flow in sickle cell disease. Stroke 1991; 22(1): 27-30

34. Mallouh AA, Qudah A. Acute splenic sequestration together with aplastic crisis caused by human parvovirus B19 in patients with sickle cell disease. J Pediatr. 1993; 122(4): 593-5

35. Dean D, Neumayr L, Kelly DM et al. Chlamydia pneumoniae and acute chest syndrome in patients with sickle cell disease. J Pediatr Oncol. 2003; 25(1): 46-55

36. Yates AM, Hankins JS, Morther NA, Aygun B, Ware RE. Simultaneous acute splenic sequestration and transient aplastic crisis in children with sickle cell disease. Pediatr Blood Cancer. 2009; 53(3): 479-481

37. Quinn CT, Variste J, Dowling MM. Hemoglobin oxygen saturation is a determinant of cerebral artery blood flow velocity in children with sickle cell anemia. Br J Haematol. 2009; 145(4): 500-505

38. Aliefendioglu D, Yilmaz S, Misirlioglu ED, Saygi S, Ozdogan S, Kocak U. Do cerebral blood flow velocities change in iron deficiency anemia? J Pediatr Hematol Oncol. 2007; 29(11): 747-51

39. Chistiakov DA, Orekhov A.N, Bobryshev YV. Effects of shear stress on endothelial cells: go with the flow. Acta Physiol (Oxf). 2017; 219(2): 382-408

40. Ismail A, Yusuf AA, Kuliya-Gwarzo A, Ahmed SG, Tabari AM, Abubakar SA. Correlating transcranial arterial Doppler velocities with haematologic parameters and haemolytic indices of Nigerian children with sickle cell anaemia. Ultrasound 2019; 27 (2): 101-110

41. Adekunle MO, Diaku-Akinwumi IN, Animasahun AB, Njokanma OF, Akodu OS, Ubuane PO. Predictors of cerebral blood flow velocity in children with sickle cell anaemia in Lagos, Nigeria. Journal of Medical and Health Sciences 2017; 6 (2): 61

42. Villagra J, Shiva S, Hunter LA, Machado RF, Gladwin MT, Kato GJ. Platelet activation in patients with sickle disease, hemolysisassociated pulmonary hypertension, and nitric oxide scavenging by cell-free hemoglobin. Blood 2006; 110(6): 2166-2172

43. Okocha E, Onwubuya E, Osuji C, Ahaneku G, Okonkwo U, Ibeh $\mathrm{N}$ et al. Disease severity scores and haemogram parameters in Nigerian sickle cell disease patients. J Blood Disord Transfus 2015, 6:324

44. Colombatti R, Padayachee S, MacMahon C, Momi S, Hemmaway CJ, Inusa B. Cerebral blood velocity is associated with increased leukocyte count and cystolic blood pressure in HbSS but not HbSC. Blood. 2015; 126(23): 989 
45. Rothman SM, Fulling KH, Nelson JS. Sickle cell anemia and central nervous system infarction: a neuropathological study. Ann Neurol. 1986; 20(6): 684-90

46. Henderson JN, Noetzel MJ, McKinstry RC, White DA, Armstrong M, DeBaun MR. Reversible posterior leukoencephalopathy syndrome and silent cerebral infarcts are associated with severe acute chest syndrome in children with sickle cell disease. Blood 2003; 101(2): 415-419 